\title{
Risks in Supply Chain Management and its Mitigation
}

\author{
Girish Gupta ${ }^{1}$, Vinay Kumar Sahu ${ }^{2}$,A.K.Khandelwal ${ }^{3}$ \\ ${ }^{1}$ (Department of Mechanical Engg, MNNIT Allahabad \\ ${ }^{2}$ (Department of Mechanical Engg, MNNIT Allahabad) \\ ${ }_{3}^{3}$ (Department of Mechanical Engg, CEC Bilaspur)
}

\begin{abstract}
Supply chain risks, vulnerabilities, complexity and uncertainties have emerged as key challenges to supply chain management. Supply chain risk management assumes importance in making the organizations understand that their risk sensitivity is dependent on other constituents of their supply chain. These risks are prone to disruptions, Forecast inaccuracies, breakdowns, economic and political changes, and disasters leading to higher risks and making supply chain management difficult. The present study categorized and refined the supply chain risks sources and its mitigation strategies for dealing with these risks. Fuzzy Analytical hierarchical process was utilized to determine the relative weights of risks which are subsequently used to rank the risk on the basis of their impact on supply chain. Understanding the priorities would help the firm to accord importance and develop suitable strategies to manage supply chain risks.
\end{abstract}

Keywords: - Supply Chain Risk, AHP, Fuzzy AHP

\section{INTRODUCTION}

Modern supply chains are very complex, and recent lean practices have resulted in these networks becoming more vulnerable. For instance, there is often little buffer inventory and any disruption can have a rapid impact on the supply process. These disruptions can have many different sources: natural disasters, strikes, terrorism attacks, etc. Supply chain risks, vulnerabilities and uncertainties have become topical issues in the last few years. The adoption of supply chain management principles by many organizations has resulted in more networks, highly dependent organizations at the same time resulted in increased vulnerabilities of supply chains. Supply chains are vulnerable to risk that arise from problems in coordinating supply and demand [21], Supply chain risk management has become a necessity for many firms. Globalization, improved infrastructure and information technology has led supply chains to become longer and more complex, resulting in higher supply chain vulnerability [35], [36]. Supply chain disruptions and related issue as supply chain risk can potentially harmful and costly for the whole supply chain.

According to Juttner, Peck and christofer [20] Supply Chain risks are divided in two different aspects: risk and uncertainty sources and risk consequences which mean risk impacts on business. Sinha et al. Classified four areas of risks which include standards, supplier, technology, and practices. In each of these four areas, there are a number of supply chain risks that could happen. Finch [13] classified risks into three broad categories which include the three levels of coverage: application level, organizational level, and inter-organizational level. At the application level, the risks include natural disasters, accidents, deliberate acts, data/information security risks, and management issues. At the organizational level, such risks as legal and strategic changes in decisions could happen, while at the inter-organizational level, there are possible uncertainty from the outside of the organization which could pose risks.Norrman and Lindroth [25] we categorize the type of risks addressed in the SCRM papers into operational accidents, operational catastrophes, and strategic uncertainty. The operational accidents are those affecting the operational process or resources related to logistics / supply chain, such as fires, truck accidents, machine failures, labor strikes, etc. Chopra and Sodhi [8] broadly categorized, potential supply chain risks include delays, disruption, forecast inaccuracies, system breakdowns, intellectual property, procurement failures, inventory problem and capacity issue. Spekman and Davis categorized into risk in the Supply risks, inventory, information flow, security, opportunistic behavior, corporate social responsibility. Peck [20] categorized into risks exist at different levels-product/ process, assets, organizations and interorganizational networks, environmentTang [35] who categorized supply chain risks into operations and disruptions risks. The operations risks are associated with uncertainties inherent in a supply chain, which include demand, supply, and cost uncertainties while disruption risks are those caused by major natural and man-made disasters such as flood, earthquake, tsunami, and major economic crisis.Cucchiella and Gastaldi [11] divided supply chain risks into categories of internal (involving such issues as capacity variations, regulations, information delays, and organizational factors) and external (market prices, actions of competitors, manufacturing yield and costs, supplier quality, and political issues) Manuj and Mentzer, having, present a generic framework for the categorization of risk in global supply chains into the following broad classes: supply 
risks, operational risks, demand risks, security risks, macro risks, policy risks, competitive risks, and resource risks.

Juttner et al [20] suggested that cooperation with supply chain partners is one of the mitigation strategies for supply chain risks. The cooperation can be in terms of joint efforts to improve supply chain visibility and understanding, joint efforts to share risk related information, and joint efforts to prepare supply chain continuity plans. Dropping specific products, geographical markets, suppliers, or customers can be considered as a way to avoid risks. Chopra and Sodhi [8] highlight mitigation strategies for different types of risks, which manufacturing organizations apply to deal with uncertainty. They identify drivers for a wide variety of different risks and pinpoint alternative proactive mitigation strategies for each corresponding risk use in the excess capacity, increased flexibility, increased capability, increased responsiveness, aggregate pool demand, additional inventory, redundant suppliers. Tang [35], [36] suggested that robust strategies for mitigating supply chain disruptions and highlighted that these strategies not only can manage the inherent fluctuations efficiently regardless of the occurrence of major disruptions but also lead to a more resilient supply chain in the face of major disruptions. There are four basic approaches that have been reported to mitigate the impact of supply chain risks: supply management, demand management, product management, and information management that a firm could deploy through a coordinated/collaborative mechanism. Supply chain risk management (SCRM) is therefore a field of intensify importance and is aimed at developing approaches to the identification, assessment, analysis and treatment of areas of vulnerability and risk in supply chains Neiger et al., [24] Supply chain risk management approaches seek to measure the supply chain structure, use the findings to predict disruption. The results are then used to prepare proper mitigation and response strategies for supply chain risk management process.

In this paper, has piloted to identify different risk issues and their mitigation approaches leading to two aspects for the study. According to behavior of risks they appear in supply chain management. In the, Fuzzy Analytical Hierarchy Process (F-AHP) has used to evolve the robust strategies for mitigating the risks in the organizations. Fuzzy Analytical hierarchical process (F-AHP) is utilized to determine the relative weights of risks which are subsequently used to prioritize them. Understanding the priorities would help the firm to accord importance and develop suitable strategies to manage supply chain risks according to their relative importance.

\section{RESEARCH METHOD}

In the previous chapter, different risk and robust strategies for mitigating risks in supply chain have been depicted that were reported in the introduction. This chapter contains methodology used in this paper for evaluating and ranking risk the in supply chain management. This chapter deals with the application of Fuzzy Analytical hierarchy process (FAHP) to evolve the risks in supply chain and it will facilitate to rank the risks. For the purpose, survey was made to assign the weight through questionnaire.

\subsection{Analytical Hierarchy Process}

The AHP developed by saaty is a robust and flexible multi-criteria decision analysis methodology.Analytic hierarchy process (AHP) is a powerful method to solve complex decision problems. Any complex problem can be decomposed into several sub-problems using AHP in terms of hierarchical levels where each level represents a set of criteria or attributes relative to each sub-problem. The AHP method is a multicriteria method of analysis based on an additive weighting process, in which several relevant attributes are represented through their relative importance.Through AHP, the importance of several attributes is obtained from a process of paired comparison, in which the relevance of the attributes or categories of drivers of intangible assets are matched two-on-two in a hierarchic structure.However, the pure AHP model has some shortcomings. They pointed out that the AHP method is mainly used in nearly crisp-information decision applications; the AHP method creates and deals with a very unbalanced scale of judgment; the AHP method does not take into account the uncertainty associated with the mapping of human judgment to a number by natural language; the ranking of the AHP method is rather imprecise; and the subjective judgment by perception, evaluation, improvement and selection based on preference of decision-makers have great influence on the AHP results.

\subsection{FUZZY ANALYTICAL HIERARCHY PROCESS}

To overcome the AHP limitations, several researchers have integrated fuzzy set theory with AHP to consider the uncertainty. Larhoven and Pedryez have compared fuzzy ratio described by triangular membership function and the logarithmic least square method to obtain element sequencing. Buckley has determined fuzzy priorities of comparison ratio whose membership function were trapezoidal. Chang has introduce a new approach for handling of fuzzy AHP with the use of triangular fuzzy number for pair-wise comparison scale of fuzzy AHP and use extent analysis method evaluating weapon system using fuzzy AHP based on entropy weight calculation. 
Chan et.al has reported that most decision-makers tend to give assessments based on their knowledge, past experience and subjective judgments. Importance of different strategies for mitigating risks contains ambiguity and multiplicity of meaning as these descriptions are usually linguistic and vague. It is also recognized that human assessment on qualitative attributes is always subjective and thus imprecise.

Buckley's fuzzy AHP has been used an evolutionary algorithm to calculate the weights with the trapezoidal fuzzy numbers. In order to simplify the fuzzy AHP process for industry from the practical and feasible viewpoints, the fuzzy AHP based on the fuzzy interval arithmetic with triangular fuzzy numbers and confidence index $\alpha$ with interval mean approach to determine the weights for evaluative elements have been proposed. The flow chart has been divided into five phases: planning, fuzzyfication, fuzzy operations, defuzzification and analysis \& confirmation.

\subsection{FUZZY SET THEORY}

Fuzzy set theory introduced by Zadeh is used to represent the vagueness of human thinking; it expands traditional logic to include instances of partial truth. In traditional set theory, elements have either complete membership or complete non-membership in a given set. With fuzzy set theory, intermediate degrees of membership are allowed. The coding of the degree of membership to each of the elements in the set is defined as the membership function of the fuzzy set.

The fuzzy set theory allows the membership functions to operate over the range of real numbers $[0,1]$. A fuzzy set is defined by a membership function and all the information about a fuzzy set is described by its membership function. The membership function maps elements (crisp inputs) in the universe of discourse (interval that contains all the possible input values) to elements degrees of membership) within a certain interval, which is usually $[0,1]$. Then, the degree of membership specifies the extent to which a given element belongs to a set or is related to a concept. The most commonly range used for expressing degree of membership is the unit interval $[0,1]$. If the value assigned is 0 , the element does not belong to the set (it has no membership). If the value assigned is 1 , the element belongs completely to the set (it has no membership). Finally, if the value lies within the interval $[0,1]$, the element has a certain degree of membership (it belongs partially to the fuzzy set). A fuzzy set, then, contains elements that have different degrees of membership in it. The main characteristic of fuzziness is the grouping of individuals into classes that do not have sharply defined boundaries. The uncertain comparison judgment can be represented by the fuzzy number.

\subsection{FUZZY NUMBER}

A fuzzy number is a special fuzzy set $F=\left\{\left(x, \mu_{\mathrm{F}}(x)\right), x \in R\right\}$, where $x$ takes it values on the real line, $R:-\infty<x$ $<+\infty$ and $\mu(x)$ is a continuous mapping from $R$ to the closed interval $[0,1]$.A triangular fuzzy number denoted as $\mathbb{M}=(a, b, c)$, where $\mathrm{a} \leq b \leq c$ has the following triangular type membership function;

$\mu_{F}(x)=\left\{\begin{array}{cc}0 & x<a \\ \frac{x-a}{b-a} & a \leq x \leq b \\ \frac{c-x}{c-b} & b \leq x \leq c \\ 0 & x>c\end{array}\right.$

In this study, triangular fuzzy numbers, 1 to 9 , have been used to represent subjective pair wise comparisons of various types of risks. A tilde " $\sim$ " is placed above a symbol if the symbol represents a fuzzy set. In order to take the imprecision of human qualitative assessments into consideration; the five triangular fuzzy numbers are defined with the corresponding membership function as shown in Figure 2.1 and Table-1.

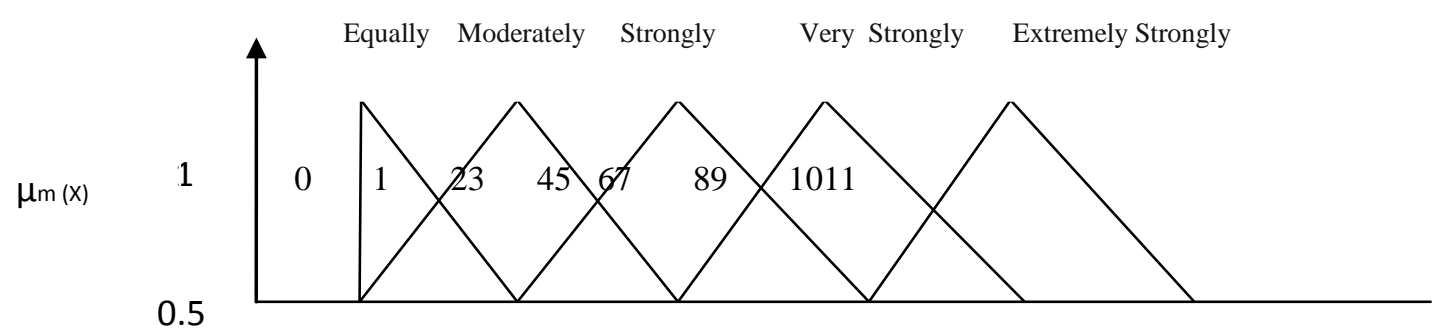

Figure 1: The Membership functions of triangular fuzzy numbers 1357 and 9 
TABLE 1 : DEFINITION AND MEMBERSHIP FUNCTION OF FUZZY NUMBERS

\begin{tabular}{|c|c|c|c|}
\hline $\begin{array}{c}\text { Intensity of } \\
\text { Importance }\end{array}$ & Fuzzy number & Definition & $\begin{array}{c}\text { Membership } \\
\text { function }\end{array}$ \\
\hline 1 & $\widetilde{1}$ & Equally important/preferred & $(1,1,3)$ \\
\hline 3 & $\widetilde{3}$ & Moderately more important/preferred & $(1,3,5)$ \\
\hline 5 & $\widetilde{5}$ & Strongly more important/preferred & $(3,5,7)$ \\
\hline 7 & $\widetilde{7}$ & Very strongly more important/preferred & $(5,7,9)$ \\
\hline 9 & $\widetilde{q}$ & Extremely more important/preferred & $(7,9,11)$ \\
\hline
\end{tabular}

\subsection{STEPS OF FUZZY AHP}

The AHP method is also known as an eigenvector method. It indicates that the eigenvector corresponding to the largest eigen value of the pair wise comparisons matrix provides the relative priorities of the factors, and preserves ordinal preferences among the alternatives. This means that if an alternative is preferred to another, its eigenvector component is larger than that of the other. A vector of weights obtained from the pair wise comparisons matrix reflects the relative performance of the various factors. In the fuzzy AHP triangular fuzzy numbers are utilized to improve the scaling scheme in the judgment matrices, and interval arithmetic is used to solve the fuzzy eigenvector Buckley the procedure of this the approach is as follows:

Step 1 Construct the hierarchy structure model.

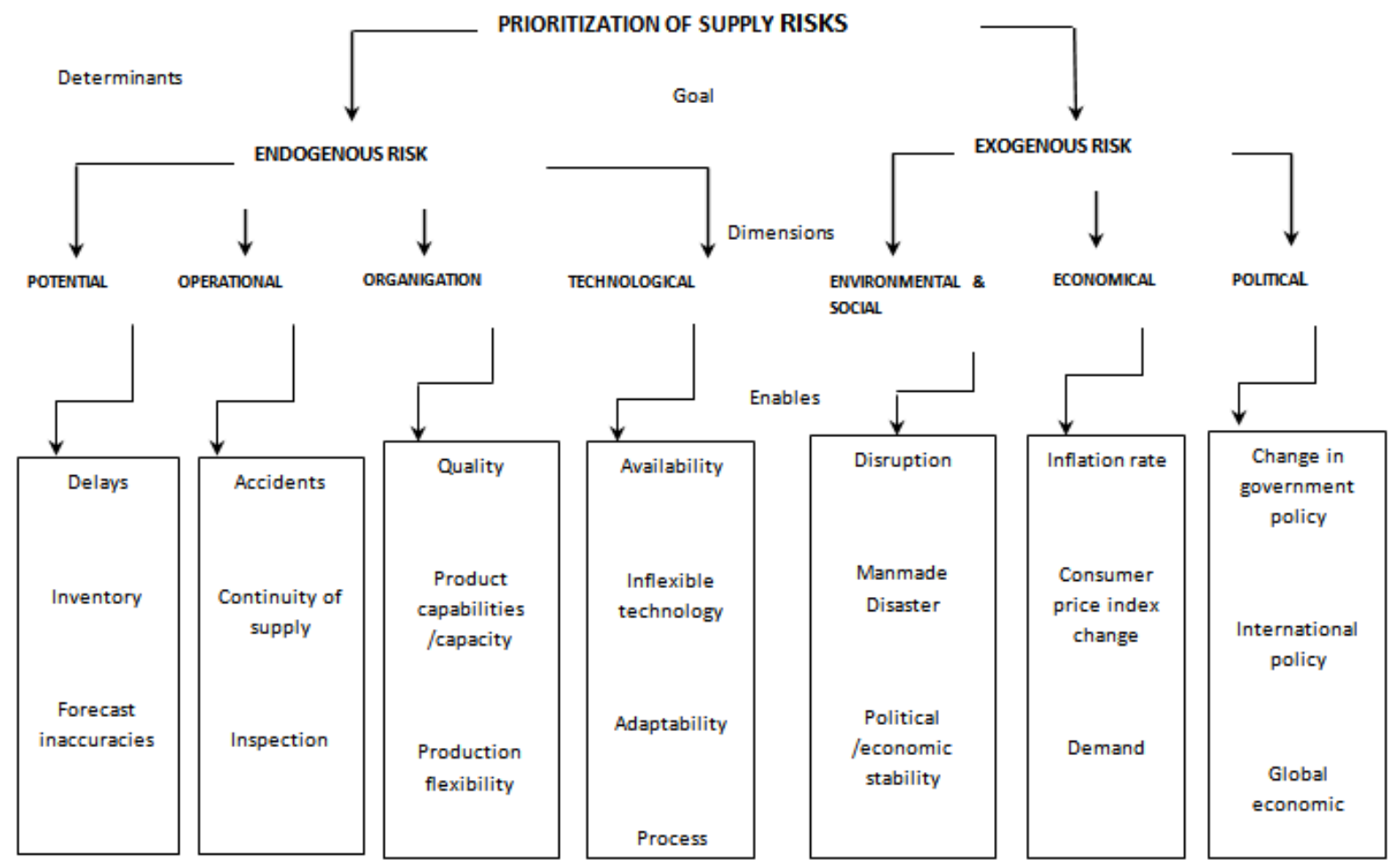

Fig. 2 The Hierarchical Model.

Step 2 Comparing the performance score: Triangular fuzzy numbers $(\widetilde{1}, \widetilde{357}$ and $\widetilde{9})$ are used to indicate the relative strength of each pair of elements in the same hierarchy.

Step 3 Constructing the fuzzy comparison matrix: By using triangular fuzzy numbers, via pair wise comparison, the fuzzy judgment matrix $\widetilde{\mathbb{A}}\left(\mathrm{a}_{\mathrm{ij}}\right)$ is constructed as equation 2 ; 


$$
A=\left[\begin{array}{cccccc}
1 & \widetilde{a}_{12} & \widetilde{a}_{1 a} & \ldots & \widetilde{a}_{1(n-1)} & \widetilde{a}_{1 n} \\
\widetilde{a}_{12} & 1 & \widetilde{a}_{2 a} & \ldots & \widetilde{a}_{2(n-1)} & \widetilde{a}_{2 n} \\
\vdots & \vdots & \vdots & \vdots & \vdots & \vdots \\
\vdots & \vdots & \vdots & \ldots & \vdots & \vdots \\
\tilde{a}_{(n-1) 1} & \widetilde{a}_{(n-1) 2} & \widetilde{a}_{(n-1) a} & \ldots & 1 & \widetilde{a}_{(n-1) n} \\
\widetilde{a}_{n 1} & \widetilde{a}_{n 2} & \widetilde{a}_{n 1} & \ldots & \widetilde{a}_{n(n-1)} & 1
\end{array}\right]
$$

Where $\widetilde{a}_{i j}=\left\{\begin{array}{l}1 \\ \widetilde{1}, \widetilde{\jmath_{s}} \widetilde{5}_{v}, \widetilde{7}, \widetilde{q} \text { or } \widetilde{1}^{-1}, \widetilde{3}^{-1}, \widetilde{5}^{-1}, \widetilde{7}^{-1}, \widetilde{q}^{-1}\end{array}\right.$

$$
i=j
$$

$i \neq j$

Step 4 Estimating the degree of optimism for $\widetilde{\mathrm{A}}$.

Degree of satisfaction for the judgment matrix $\widetilde{A}$ is estimated by the index of optimism $\mu$. The larger value of the $\mu$ indicates the higher degree of optimism. The index of optimism is a linear convex combination defined as:

$\hat{a}_{i j}^{\alpha}=\mu a_{i j \mu}^{\alpha}+(1-\mu) a_{i j p s}^{\alpha} \quad \forall \mu \in[0,1]$

While $\alpha$ is fixed, following crisp judgment matrix can be obtained after setting the index of optimism, $\mu$, in order to estimate the degree of satisfaction

$\widetilde{A}=\left[\begin{array}{cccc}1 & \hat{a}_{12}^{\alpha} & \ldots & \hat{a}_{1 n}^{\alpha} \\ \hat{a}_{21}^{\alpha} & 1 & \cdots & \hat{a}_{2 n}^{\alpha} \\ \cdots & \ldots & \cdots & \vdots \\ \hat{a}_{n 1}^{\alpha} & \hat{a}_{n 2}^{\alpha} & \cdots & 1\end{array}\right]$

Step 5 Solving fuzzy eigen value

A fuzzy eigen value, $\lambda$ is a fuzzy number solution to

$\widetilde{A} \widetilde{\mathbb{x}}=\widetilde{\pi} \widetilde{\mathrm{x}}$

where is $\widetilde{\mathrm{A}} \mathrm{n} \times \mathrm{n}$ fuzzy matrix containing fuzzy numbers $\widetilde{\mathbf{a}}_{\mathrm{ij}}$ and $\widetilde{\mathrm{x}}$ is a non-zero $\mathrm{n} x \mathrm{1}$, fuzzy vector

containing fuzzy number $\widetilde{\mathbf{x}}_{\mathrm{i}}$. To perform fuzzy multiplications and additions by using the interval arithmetic and $\alpha$ - cut, the equation 5 becomes equivalent to

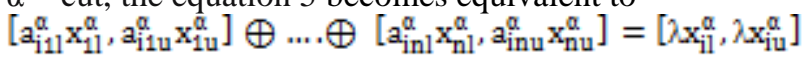

$\widetilde{\mathrm{A}}=\left[\widetilde{\mathbf{a}}_{\mathrm{ij}}\right], \widetilde{\mathbb{x}}^{\mathrm{t}}=\left(\widetilde{\mathbf{x}}_{1}, \ldots \ldots ., \widetilde{\mathrm{x}}_{\mathrm{n}}\right)$

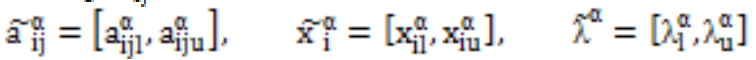

For $0<\alpha \leq 1$ and all $i, j$, where $i=1,2, \ldots ., n$ and $j=1,2, \ldots \ldots, n$

Step 6 Determining the weights for criteria

The Eigen value method is used for calculating the eigenvector or weighting vector for each pair-wise matrix. The eigenvector is calculated by fixing the $\mu$ value and identifying the maximal Eigen value. (Saaty, (1980))

$\lambda \max$ is calculated then Normalization of both the matrix of paired comparisons and evolution of priority weights (approximate attribute weights). In order to control the results of the method, the consistency ratio for each of the matrices and overall inconsistency for the hierarchy are calculated. The deviations from consistency are expressed by the following equation:

$C I=\frac{\lambda \max -n}{n-1}$

Where: $\mathrm{CI}$ is consistency index.

The consistency ratio (CR) is used to estimate directly the consistency of pair wise comparisons.;

$C R=\frac{C I}{\text { RI }}$

Where: $\mathrm{RI}$ is selected from table 2 according to the rank of the matrix.

Table-2: Average Index for Randomly Generated Weights

\begin{tabular}{|l|l|l|l|l|l|l|l|l|l|}
\hline Matrix Rank & 2 & 3 & 4 & 5 & 6 & 7 & 8 & 9 & 10 \\
\hline RI & 0.00 & 0.58 & 0.90 & 1.12 & 1.24 & 1.35 & 1.41 & 1.45 & 1.49 \\
\hline
\end{tabular}

The comparisons are acceptable if $\mathrm{CR}<0.1$. If the consistency test is not passed, the original values in the pair wise comparison matrix must be revised by the decision maker.

Step 7 Ranking the Criteria

Ranking are provided on the basis of the final score of the enablers. Final score are calculated with the help of relative importance weight of dimension and relative important weight of enabler. Further, a survey was carried 
out to find out the importance of the enablers in the industries using Likert scale (1-5). The mean of data is calculated for different enablers. The final score is defined as:

$F S_{k}=\left(A_{d k} * A_{k}\right) S M_{k}$

Where

$F S_{k}=$ Final score of enabler (strategy) $\mathrm{k}$

$A_{d k}=$ Relative important weight of dimension d of enabler k

$A_{k}=$ Relative important weight of enabler k, $S M_{k}=$ Survey mean of the enabler k

\section{RESULTS AND ANALYSIS}

A structured questionnaire was framed to collect the responses of industries. These questions were framed on a five point Likert scale. These questionnaires were mailed to different industries throughout the country.It included industries involved in the manufacturing, power plant etc. to evaluate the different risks. Final score was calculated from Equation 9. Final score of various enablers (strategies) are shown in Table1. Ranking is provided according to their final score.The analysis shows that among Endogenous Risk and Exogenous Risk,on comparison We get dimensions with $83.33 \%$ of Endogenous risk and that followed by Exogenous risk $16.67 \%$. Under this subcategorization Disruption is ranked number one and its final score value is found to be higher than other risks. It indicates that in the recent years, disruption is more common in supply chain, due to increasing supply chain complexity and demand for more agility that increases supply chain risk. To deal this disruption risks we identify supply chain vulnerability points. and have contingency plans for them, even add inventories in mitigation of these disruption risks. The second important risk from analysis under the potential risk list is Forecast inaccuracies. Forecast inaccuracy risks result from a mismatch between a company projections and actual demand. If forecast are too low, products might not be available to sell. Forecast that are too high result in excess inventories and, inevitably, causes price mark-downs. Long lead times, seasonal demand, high product variety and smaller Bullwhip effect or information distortion all increase forecast error. Better planning and coordination of supply demand; flexible capacity, increased responsiveness and aggregate pool demand has to be used to mitigate this forecast error in the supply chain.

Table. 3 Sensitivity levels of risks

\begin{tabular}{|c|c|c|c|c|c|c|c|c|c|}
\hline $\begin{array}{c}\text { Main } \\
\text { Criterion } \\
\text { Determina } \\
\text { nt }\end{array}$ & $\mathbf{A}_{\mathrm{dk}}$ & $\begin{array}{c}\text { Sub } \\
\text { criterion } \\
\text { Dimensions }\end{array}$ & $\mathbf{A}_{\mathbf{k}}$ & $\begin{array}{l}\text { Sub-sub } \\
\text { criterion } \\
\text { Enables }\end{array}$ & $\mathbf{A}_{\mathrm{k}}$ & $A_{d h} \times A_{k_{1}} \times A_{k_{2}}$ & $S M_{k}$ & $F S_{k}$ & Rank \\
\hline \multirow{16}{*}{$\begin{array}{c}\text { Endogeno } \\
\text { us risk }\end{array}$} & \multirow{16}{*}{$\begin{array}{c}0.833 \\
3\end{array}$} & \multirow{4}{*}{$\begin{array}{l}\text { Potential } \\
\text { Risk }\end{array}$} & \multirow{4}{*}{$\begin{array}{c}0.592 \\
8\end{array}$} & Delay & 0.5824 & 0.28770 & 1.02671 & 0.29539 & 3 \\
\hline & & & & Inventory & 0.2170 & 0.10722 & 1.07583 & 0.11535 & 10 \\
\hline & & & & Forecast & 0.1441 & 0.07124 & 4.2562 & 0.30305 & 2 \\
\hline & & & & Capacity & 0.0563 & 0.02785 & 4.9123 & 0.13681 & 7 \\
\hline & & \multirow{4}{*}{$\begin{array}{c}\text { Operational } \\
\text { Risk }\end{array}$} & \multirow{4}{*}{$\begin{array}{c}0.279 \\
3\end{array}$} & Accidents & 0.5683 & 0.13231 & 1.00857 & 0.13344 & 9 \\
\hline & & & & C.OS & 0.2629 & 0.06122 & 3.12657 & 0.19141 & 5 \\
\hline & & & & Inspection & 0.1103 & 0.05452 & 1.05894 & 0.05773 & 14 \\
\hline & & & & Maintenance & 0.0582 & 0.02877 & 1.45234 & 0.03461 & 21 \\
\hline & & \multirow{4}{*}{$\begin{array}{c}\text { Organizatio } \\
\text { n Risk }\end{array}$} & \multirow{4}{*}{$\begin{array}{c}0.098 \\
4\end{array}$} & Quality & 0.6064 & 0.04977 & 4.53265 & 0.22560 & 4 \\
\hline & & & & $\begin{array}{c}\text { Prod. } \\
\text { Capability }\end{array}$ & 0.1712 & 0.01405 & 4.8673 & 0.07641 & 12 \\
\hline & & & & $\begin{array}{c}\text { Prod. } \\
\text { flexibility }\end{array}$ & 0.1712 & 0.01405 & 3.7543 & 0.05277 & 15 \\
\hline & & & & $\begin{array}{c}\text { Management } \\
\text { re. }\end{array}$ & 0.0509 & 0.00417 & 4.53412 & 0.03818 & 17 \\
\hline & & \multirow{4}{*}{$\begin{array}{l}\text { Technologic } \\
\text { al Risk }\end{array}$} & \multirow{4}{*}{$\begin{array}{c}0.049 \\
8\end{array}$} & Availability & 0.6064 & 0.02520 & 1.45625 & 0.03670 & 18 \\
\hline & & & & Complexity & 0.2038 & 0.00847 & 3.75689 & 0.03182 & 19 \\
\hline & & & & Adaptability & 0.1252 & 0.00520 & 3.5753 & 0.01861 & 23 \\
\hline & & & & $\begin{array}{c}\text { Pro./product } \\
\text { chan. }\end{array}$ & 0.0624 & 0.00259 & 4.8567 & 0.01260 & 24 \\
\hline \multirow{12}{*}{$\begin{array}{c}\text { Exogenous } \\
\text { risk }\end{array}$} & \multirow{12}{*}{$\begin{array}{c}0.166 \\
7\end{array}$} & \multirow{4}{*}{$\begin{array}{c}\text { Environmen } \\
\text { tal Risk }\end{array}$} & \multirow{4}{*}{$\begin{array}{c}0.834 \\
6\end{array}$} & Disruption & 0.5475 & 0.06265 & 4.85126 & 0.36954 & 1 \\
\hline & & & & Man made & 0.3060 & 0.03502 & 3.18923 & 0.13579 & 8 \\
\hline & & & & Political & 0.1014 & 0.01161 & 3.13412 & 0.04424 & 16 \\
\hline & & & & Market Ch. & 0.0449 & 0.00514 & 4.2175 & 0.08783 & 11 \\
\hline & & \multirow{4}{*}{$\begin{array}{c}\text { Economical } \\
\text { Risk }\end{array}$} & \multirow{4}{*}{$\begin{array}{c}0.359 \\
5\end{array}$} & Inflation & 0.5981 & 0.02107 & 4.67534 & 0.16758 & 6 \\
\hline & & & & Consumer & 0.2677 & 0.00943 & 4.56742 & 0.07328 & 13 \\
\hline & & & & Demand & 0.1330 & 0.00468 & 4.75689 & 0.03793 & 20 \\
\hline & & & & Foreign & 0.0416 & 0.00146 & 3.75523 & 0.00938 & 27 \\
\hline & & \multirow{4}{*}{$\begin{array}{l}\text { Political } \\
\text { Risk }\end{array}$} & \multirow{4}{*}{$\begin{array}{c}0.071 \\
0\end{array}$} & $\begin{array}{c}\text { Change. In } \\
\text { Gov.Po. }\end{array}$ & 0.5049 & 0.00860 & 4.85765 & 0.02904 & 22 \\
\hline & & & & $\begin{array}{c}\text { International. } \\
\text { Po. } \\
\end{array}$ & 0.2748 & 0.00468 & 3.5978 & $\begin{array}{c}0.01170 \\
6 \\
\end{array}$ & 25 \\
\hline & & & & $\begin{array}{c}\text { Global } \\
\text { economy }\end{array}$ & 0.1686 & 0.00282 & 4.7545 & $\begin{array}{c}0.00111 \\
7 \\
\end{array}$ & 26 \\
\hline & & & & $\begin{array}{c}\text { Terrorism } \\
\text { attack }\end{array}$ & 0.0516 & 0.00087 & 3.78975 & $\begin{array}{c}0.00023 \\
5 \\
\end{array}$ & 28 \\
\hline
\end{tabular}




\section{CONCLUSION}

This is a prospective study on identification of risks and it's mitigation in supply chain management. The main objective was identifying the risks and it's mitigation in supply chain. The risks in supply chain have been ranked using Fuzzy AHP. In Fuzzy AHP process the hierarchical model was constructed on the basis of the literature review. Prioritization of risks is based on discussion with the experts and survey data received through questionnaires from various industries in India. In this risk categorizing the main criteria Endogenous Risk got $83.33 \%$ weightage and Exogenous Risk got $16.67 \%$ weightage as per the pair wise comparison in Fuzzy AHP calculation. We may now conclude that the likelihood of factors of Endogenous Risk is high and that of Exogenous risk is low. The analysis showed that the risk sub categories disruption, forecast inaccuracies and delay have high impact on the supply chain management. Ranks were allotted to the risks on the basis of their impact on supply chain. The disruption, forecast inaccuracies, delay, quality, continuity of supply, got higher ranks compared to others.Identifying supply chain vulnerability points, having contingency plans, and adding inventories, adding capacity, increase flexibility, responsiveness, Managing demand, promotions incentives for customers, cost reduction in operations and capacity, better planning and coordinating, all these the mitigate this risks in supply chain. Further on the research the model developed other fuzzy approaches such as Fuzzy Topsis ranking method can be used to prioritize these supply chain risks. In further model we can also consider MonteCarlo-based simulation software for calculating the risks. A risk is inherent in every link with firm's supply chain hence it is impossible to completely mitigate a supply chains' risks. But by understanding the sources of risk and prioritizing them, firms can take a proactive view for reducing and managing these risks.

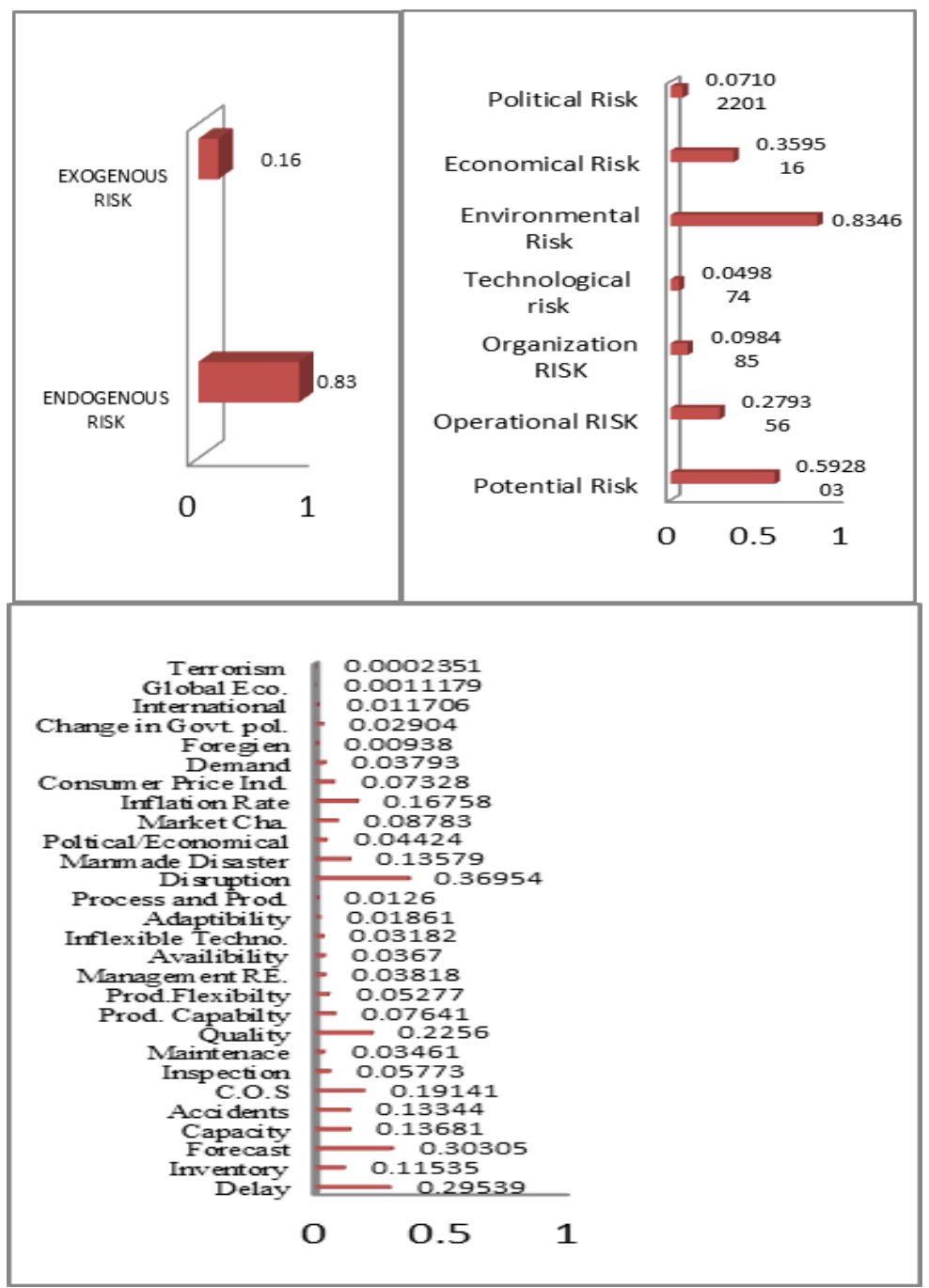

Fig.3 Sensitivity levels of risks 


\section{ACKNOWLEDGEMENT}

I wish to express my sincere thanks to Mr. Harish Chandra Yadav and Mr. Sandarbh Shukla P.h.D. Scholar of the Mechanical Engineering Department for their cooperation and valuable suggestion in each stage of my work.

\section{REFERENCES}

[1] Adegoke Oke, Mohan Gopalakrishnan., "Managing disruptions in supply chains: A case study of a retail supply chain". Int. J. Production Economics 118, 168-17. 2008.

[2] Albayrak, E., \& Erensal, Y. C. "Using analytic hierarchy process (AHP) to improve human performance. An application of multiple criteria decision Making problem". Journal of Intelligent Manufacturing, 15, 491-503, 2004.

[3] Anish Sachdeva, Dinesh Kumar. "Multi-factor failure mode critically analysis using TOPSIS". Islamic Azad University, South Tehran Branch, January 2009, Vol. 5, No. 8, 1-9, 2009.

[4] Bimal Nepal Om P. Yadav, Alper Murat, "A fuzzy-AHP approach to prioritization of CS attributes in target planning for automotive product development". Expert Systems with Applications 37 6775-6786, 2010.

[5] C.K.Kwong, H. Bai, "A fuzzy approach to determine of importance weight of customer requirements in quality function deployment”. Journal of Intelligent manufacturing, 13,367-377, 2002.

[6] Chia-Chi Sun, "A performance evaluation model by integrating fuzzy AHP and fuzzy TOPSIS methods". Expert Systems with Applications 37, 7745-7754. 2010.

[7] Christopher, M., \& Lee, H. "Mitigating supply chain risk through improved confidence". International Journal of Physical Distribution \& Logistics Management, 34(5), 388-396, 2004.

[8] Chopra, S., Sodhi, M., "Managing risk to avoid supply-chain breakdown". Sloan Management Review 46 (1), 53-61,2004.

[9] Chopra, S., Meindl, P.\& Kalra, D. V. "Supply Chain Management: Strategy, Planning, and Operatio", Printing Hall, NJ, Fourth Edition. 2006.

[10] Constantin Blome, Tobias Schoenherr., "Supply chain risk management in financial crises-A multiple case-study approach" 134, 43-57. Int. J. Production Economics 134 (2011) 43-57,2011.

[11] Cucchiella, F., \& Gastaldi, M. "Risk management in a globalised cosmetic firm". Int. J. of Logistics Economics and Globalisation, 1(1), 21-33, 2007.

[12] Donald Waters, "Supply chain Risk Management, Vulnerability and Resilience in Logistics", 2007.

[13] Finch, P. "Supply chain risk management". Supply Chain Management: An International Journal, 9(2), $183-196,2004$

[14] George A. Zsidisin, Bob Ritchie. "Supply chain risk", A Handbook of assessment, Management, and performance.

[15] Giunipero, L. C., \& Eltantawy, R. A. "Securing the upstream supply chain: a risk management approach". International Journal of Physical Distribution \& Logistics Management, 34(9), 698 - 713, 2004.

[16] Gunasekaran, A., Patel, C., McGaughey, R.E., 2004. A framework for supply chain performance measurement. International Journal of Production Economics 87 (3), 333-347.

[17] Hallikas, J., Karvonen, I., et al. "Risk management processes in supplier networks". International Journal of Production Economics 90 (1), 47-58, 2004.

[18] Jyri p.p. Vilko, Jukka M. Hallikas. "Risk assessment in multimodal supply chains". Int. J. Production Economics. , 2011.

[19] Juttner, U. "Supply chain risk management: Understanding the business requirements from a practitioner perspective". International Journal of Logistics Management, 16(1), 120-141, 2005.

[20] Juttner, U., Peck, H., \& Christopher, M. "Supply chain risk management: Outlining an Agenda for future research". International Journal of Logistics: Research and Applications, 6(4), 197-210, 2003.

[21] Kleindorfer, P. R., \& Saad, G. H. "Managing disruption risks in supply chains". Production and Operations Management, 14(1), 53-68, 2005.

[22] Liu Bochao. "Supply Chain Risk Assessment Based on AHP and Fuzzy Comprehensive Evaluation". International Conference on Management of e-Commerce and e-Government. 2010.

[23] Mihalis Giannakis, Michalis Louis. "A multi-agent based framework for supply chain risk management" 17, 23-31. Journal of Purchasing \& Supply Management 17 (2011) 23-31, 2010.

[24] Neiger, D., Rotaru, K., et al. "Supply chain risk identification with value-focused process engineering". Journal of Operations Manage- ment 27 (2), 154-168. 2009.

[25] Norrman, A., \& Lindroth, R. "Categorization of supply chain risk and risk management". In C. Brindley (Ed.), Supply chain risk, 2004. 
[26] Ou Tang, S. Nurmaya Musa., "Identifying risk issues and research advancements in supply chain risk management". 133, 25-34. Int. J. Production Economics 133 (2011) 25-34, 2010.

[27] P.K. Dey, "Project risk management: a combined analytic hierarchy process and decision tree analysis approach", Cost Engineering Journal 44 (3) 13-26, 2002.

[28] P. Dey, "Decision support system for inspection and maintenance: a case study of oil pipelines", IEEE Transactions on Engineering Management 15 (1) 47-56, 2004.

[29] P. Moeinzadeh, A. Hajfathaliha, "A Combined Fuzzy Decision Making Approach to Supply Chain Risk Assessment", International Journal of Human and Social Sciences 5:13, 2010.

[30] Paulsson, U. "Supply chain risk management". In C. Brindley (Ed.), Supply chain risk (pp. 79-96). Burlington: Ashgate Publishing Limited, 2004.

[31] Prasanta Kumar Dey "Managing project risk using combined analytic hierarchy process and risk map", Applied Soft Computing 10, 990-1000, 2010

[32] Ritchie B. \& Brindley C. "Supply chain risk management and performance: A guiding framework for future development", International Journal of Operations \& Production Management 27/3:303-322,2007.

[33] Suhaiza Zailani, Nyoman Pujawan. "Supply Chain Risk Management: Literature Review and Future Research"16 Int'l Journal of Information Systems and Supply Chain Management, 2(1), 16-33, JanuaryMarch 2009

[34] Saaty, T.L. "The Analytic Hierarchy Process", McGraw-Hill, 1980.

[35] Tang, C. S. "Perspectives in supply chain risk management". International Journal of Production Economics, 103(2), 451-488, 2006 .

[36] Tang, C. S. "Robust strategies for mitigating supply chain disruptions", International Journal of Logistics: Research and Applications, 9(1 March), 33-45, $2006 \mathrm{~b}$.

[37] Tien-Chin Wang, Yueh-Hsiang Chen, "Applying fuzzy linguistic preference relations to the improvement of consistency of fuzzy AHP”. Information Sciences 178 3755-3765. 2008.

[38] Trkman, P.,McCormack,K., "Supply chain risk in turbulent environments- A conceptual model for managing supply chain network risk" .International Journal of ProductionEconomics119(2),247-258, 2009.

[39] Wu, T., Blackhurst, J., \& Chidambaram, V. "A model for inbound supply risk analysis". Computers in Industry, 57(4), 350-365, 2006.

[40] Zsidisin, G. A., \& Ellram, L. M. "An agency theory investigation of supply risk management”. Journal of Supply Chain Management, 39(3), 15-27, 2003.

[41] Zsidisin, G. A. "A grounded definition of supply risk", Journal of Purchasing \& Supply Management, 9, 217-224, 2003a.

[42] Zsidisin, G. A. "Managerial perceptions of supply risk". Journal of Supply Chain Management, 39(1), 14$25,2003 b$.

[43] Zsidisin, G. A., Ellram, L. M., Carter, J. R., \& Cavinato, J. L. "An analysis of supply risk assessment techniques". International Journal of Physical Distribution \& Logistics Management, 34(5), 397-413, 2004. 